\title{
La participación política de los evangélicos en Chile (1999-2017)
}

Recibido: 14 de agosto 2018 Revisado: 11 de septiembre 2018

Aprobado: 26 de octubre 2018

Miguel Ángel Mansilla Chileno. Sociólogo, doctor en Antropología. Director de Revista Cultura y Religión. Director de Investigaciones e investigador del Instituto de Estudios Internacionales (INTE), Universidad Arturo Prat. Correo electrónico: mansilla.miguel@gmail.com

Luis Alberto Orellana Urtubia Chileno. Doctor en Estudios Americanos (Universidad de Santiago de Chile). Actualmente es investigador del Instituto de Estudios Internacionales (INTE) de la Universidad Arturo Prat, editor académico de la Revista Cultura y Religión, historiador del pentecostalismo chileno, fundador de la Red Latinoamericana de Estudios Pentecostales (RELEP). Correo electrónico: luis_ubl@yahoo.com

Nicolás Panotto Argentino. Magister en Antropología Social y Política. Doctorando en Ciencias Sociales (FLACSO Argentina). Temas de investigación: pentecostalismo, religión y política. Investigador Asociado del Instituto de Estudios Internacionales (INTE), Universidad Arturo Prat. Correo electrónico: nicolaspanotto@gmail.com
Resumen: El objetivo de este artículo es describir la relación que los evangélicos han construido con los políticos y la política chilena en los últimos 20 años. Para el abordaje metodológico, recurrimos a la estrategia de estudio de caso. Realizamos un relevamiento, sistematización y análisis de fuentes secundarias (notas periodísticas de medios seculares y confesionales, páginas web, bibliografía especializadas y archivos personales). Los principales resultados del artículo son: una repolitización del mundo evangélico a partir de 1999; permanentes conflictos políticos entre líderes evangélicos metropolitanos, los cuales son generalizados a todo el espectro evangélico nacional; politización del mito de la libertad de conciencia y la politización mito fundacional "Chile para Cristo".

Palabras clave: Pentecostalismo; evangélicos; política; políticos

\section{The Political Participation of Evangelicals in Chile (1999-2017)}

Abstract: The goal of this article is to describe the relationship that evangelicals have built with politicians and the politics of Chile in the last 20 years. As the methodological approach, we focus on a strategy of case study. We perform a systematization and analysis of secondary sources (journalistic notes of secular and denominational media, web sites, specialized bibliography, and personal files). The main results of the article are: a re-politicization of the evangelical world from 1999; permanent political conflicts between metropolitan evangelical leaders which are generalized to the whole national evangelical spectrum; politicization of the myth of the freedom of conscience and the politicization foundational myth "Chile for Christ".

Key words: Pentecostalism; evangelicalism; politics; politicians 


\section{Introducción}

Si bien autores abordaron la articulación entre mundo evangélico y política en Chile (D’Epinay 1968; Lagos 1988; Ossa 1991; Fediakova 2013; Mansilla y Orellana 2018), aún continúa siendo un área de vacancia. La literatura local trabajó muy escasamente las formas de participación pública de los líderes evangélicos, como también sus nuevas formas de agrupación y la reciente agenda valórica en la política. Asimismo, este desconocimiento sobre la participación política evangélica se extiende más allá de la frontera de las ciencias sociales, alcanzando a la propia sociedad chilena e incluso a los mismos evangélicos. Sólo como ejemplo, hasta noviembre del año 2017, se creía que el único diputado evangélico había sido Edmundo Salas, quien ejerció su cargo por el Distrito 45 (Región del Bio-Bio) entre 1990-2006. Según Salas, fue evangélico desde niño y se hizo militante del Partido Democracia Cristiana en 1967, en el cual ha permanecido hasta hoy. Sin embargo, la participación de los evangélicos, tanto en cargos de confianza como de elección popular, tiene una trayectoria de largo aliento.

El presidente Pedro Aguirre Cerda nombró como primera alcaldesa mujer a Graciela Contreras Barrenechea, quien por los años 1940 participaba en la Iglesia metodista; fue la primera mujer que gobernó una municipalidad capital de Sudamérica (Ortiz 2012). Otro caso importante de participación pública se dio en el Gobierno de Gabriel González Videla, en la persona del pastor Mamerto Mansilla de la Iglesia Metodista Pentecostal de Chile (IMPCH) en Temuco, quien fue nombrado Gobernador de Pitrufquén en 1946.

En cuanto a la elección popular, durante el Gobierno del Gabriel González Videla (1946-1952), localizamos a Miguel Guerrero Méndez, profesor de Estado y miembro de la IMPCH de San Carlos quien "es elegido regidor independiente entre 1948 y 1950 y luego rehusó seguir en la arena política prefiriendo el magisterio" (Revista Tribuna Cristiana 2003, 2). Asimismo, encontramos a "José Meza, predicador laico de la Iglesia Wesleyana, presidente del Sindicato Marítimo en Penco, Regidor (Alcalde) en dicho pueblo y relegado al campo de concentración de Pisagua en el año 1952" (Ossa 1990, 187). Y, finalmente, podemos mencionar al diputado mapuche de origen anglicano $\mathrm{Ve}$ nancio Coñuepán Huenchual (Partido Conservador), quien fue diputado desde 1945 hasta 1968.

El mundo evangélico tiene un extenso itinerario de vinculación con el amplio arco político. Con el centro izquierda, tuvo lazos desde el siglo XIX. Sólo por nombrar algunos ejemplos: Adolfo Oétinger Stegmyer, (1921-1924), Luterano, por Valdivia; Julio Buschman von Desauerd (1924-1930) Radical, por Valdivia, Luterano; Jorge Grob Westermayer (1924-1930) Radical por La Unión, Luterano; Carlos Schûmann Ritter, (1926-1934) Radical, Luterano por Valdivia; Carlos Hawerbuck Richter (1933-1945) Radical, Luterano, por 
Osorno; Roberto Contreras Galaz (1949-1953) Radical por Cautín, Bautista (Vilches 2017). Como se puede observar, los lazos con el centro izquierdo cambian desde la década de 1960 cuando en dicho espacio político emergen duras críticas al empresariado, a los terratenientes y a la religión, justamente tres condiciones que reunían los anglicanos y luteranos.

A partir de los efectos demonizadores hacia la izquierda por parte de la dictadura, los evangélicos de esas dos tradiciones se hermanan con la derecha política. Esto se registra con la vuelta de la democracia, en la cual políticos de esa denominación se volcarán a filiaciones en ese espectro, tales como Bruno Siebert Held (1990-1998), por Llanquihue Renovación Nacional (RN), Luterano; Rodolfo Stanger Oelkers (1998-2006) exgeneral de carabinero durante la dictadura militar y luego elegido senador, por Puerto Montt y Chiloé, Unión Democrática Independiente (UDI) y Luterano; Ena von Baer Jahn (2014-2022) UDI, por Los Lagos (reelecta por Los Ríos), Luterana; y Harry Gurgensen por el Distrito 56, Frutillar (Región de los Lagos), RN, 1994-1998.

Aunque la presencia de evangélicos en la política es una constante desde la constitución del Estado-nación chileno, ha mutado el tipo de vínculo y de participación a lo largo del tiempo y las condiciones sociopolíticas. Históricamente, los políticos evangélicos tendían a resaltar su identidad político-partidista por encima de su identidad religioso-denominacional. En cambio, en los últimos años, el mundo político evangélico se tornó diverso y mayoritariamente conservador. Algunos grupos denominacionales se lanzan a la política en búsqueda de beneficios y de prebendas para sus congregaciones. Otros intentan imponer una agenda valórica conservadora y se establecen nuevos tipos de organizaciones y de plataformas religiosas que aspiran a constituir una "bancada evangélica" similar a la brasilera. Por consiguiente, nuestro objetivo en este artículo es describir la relación que los evangélicos han construido con los políticos y la política chilena en los últimos 20 años.

Frente a ello, sostenemos que los vínculos entre evangélicos y política mutaron desde la búsqueda de legitimidad, visibilidad y reconocimiento en el espacio público chileno a la emergencia y consolidación de un sector del espectro religioso cuyo principal objetivo es la evangelización de todas las áreas sociales (política, economía, Estado y cultura); para ello, no busca apoyo de líderes políticos fuera de la iglesia, sino que ellos mismos pretenden situarse como candidatos en elecciones municipales, diputados y senatoriales, con miras a disponer de un presidente de la república evangélico en próximas décadas.

Para abordar metodológicamente nuestro objetivo, hemos recurrido, dentro de la tradición cualitativa, a la estrategia del estudio de caso (Neiman y Quaranta 2006). Específicamente, efectuamos relevamiento, sistematización y análisis de fuentes secundarias (entrevistas personales, notas periodísticas de medios seculares y confesionales, páginas web y bibliografía especializadas, y archivos personales) teniendo siempre como punto de observación prioritario la participación política de grupos evangélicos en el periodo 19992017. 


\section{La repolitización del mundo evangélico}

La desafección política mostrada por los votantes evangélicos, se concentró en sectores pentecostales hasta inicios del siglo XXI. El impacto social de la vuelta a la democracia en 1990 condujo a los líderes más jóvenes de iglesias evangélicas y pentecostales a un cambio de mentalidad, pero en especial a una nueva actitud hacia la política y el servicio público, talante que llevó a un número importante de líderes a desfilar por las iglesias mostrando sus proyectos políticos. Esto comenzó a fines del siglo XX cuando se crearon organizaciones y plataformas políticas evangélicas.

El primer evento se dio el año 1998 cuando, en el seno de los evangélicos, nace la Alianza Nacional Cristiana (ANC), con el propósito de llevar al pastor Salvador Pino Bustos como candidato en las elecciones presidenciales de 1999. En un cónclave, acordaron que su principal objetivo era promover un postulante presidencial, "para que se incorpore el pueblo evangélico a la participación del tejido social" (Prensa Evangélica 1999, 11). Salvador Pino Bus-

1. Fundador de la Iglesia Restauración, exmiembro de la Iglesia Metodista Pentecostal de Chile en San Bernardo. tos ${ }^{1}$ destacó que lo apoyaba el Comité de Referencia Pastoral. Entre los lemas estaba: "¡Con Cristo presente, Pino presidente!".

Además de este grupo de apoyo, Salvador Pino Bustos contó con un fuerte aliado: el espectro radial evangélico. Dentro de la lista, se halla el pastor Fernando Chaparro (dueño de la Radio Corporación y Portales); el pastor Rubén Sáez (propietario de la red de Radio Armonía); el pastor Italo Frígoli (dueño del Club Deportivo Hosanna) y el pastor Enrique Vilches (famoso importador de oro y dueño de la cadena de Joyerías Barón).

Pese a tratarse de un grupo de evangélicos más organizado, mostraron su inexperiencia, al querer, quizás, trasladar a la política la informalidad de la cultura religiosa pentecostal, dado que su programa de gobierno era improvisado. Entre sus propuestas, estaban: "1) Reconciliación y Concordia Social; 2) Integración; 3) Tradición y valores culturales esenciales; 4) Modernización y desarrollo económico; 5) Orden social libre y solidario" (Prensa Evangélica $1999,11)$. Esto evidenció la finitud de su propuesta, que no logró entusiasmar ni motivar a los propios evangélicos.

Así, por tercera vez, el intento de que un evangélico sea al menos candidato a presidente de la república había fracasado. Sin embargo, el propósito de llevar un candidato propio en las elecciones de 1999 fue aprovechado por ese grupo de líderes evangélicos para hacer lobby con los distintos candidatos presidenciales, a fin de lograr la tan anhelada Ley de Culto.

En este proceso, se reunieron con el candidato de centro izquierda Ricardo Lagos. Se logró un encuentro con 80 pastores evangélicos, en el cual aseguraron el apoyo de Lagos en favor de la Ley de Culto. Por otro lado, en primer lugar, Andrés Zaldívar, quien apoyaba a Lagos, prometió gestionar ayuda estatal para construir un templo evangélico. En segundo lugar, Joaquín Lavín, candidato por la derecha, ofreció un discurso en la inauguración de una igle- 
sia evangélica en Las Condes; y Arturo Frei Bolívar, independiente de derecha, habló de sus antepasados luteranos.

Como vemos, distintos candidatos trataban de buscar apoyo religioso uniéndose con ellos. De este modo, "abanderados de centro izquierda privilegiaron contactos con el mundo evangélico, mientras que Joaquín Lavín se da a conocer entre los obispos católicos" (El Mercurio 1999), lo que se tradujo en una campaña política entre el candidato evangélico y el católico. El fuerte cabildeo los llevó a lograr la Ley de Libertad e Igualdad Religiosa y de Culto, publicada en el Diario Oficial el 14 de octubre de 1999.

No sólo fue el lobby, sino también presiones públicas en periódicos, radios y calles. Lo más efectivo fue la movilización social, en tanto y en cuanto los líderes mostraron su capacidad de movilización; y los evangélicos, la de unidad frente a un tema común y relevante. Esto no sucedía desde los años 1964. Al respecto, el pastor Hermes Canales muestra que, entre 1994 y 1999, se realizó un total de seis marchas masivas: 1) El 30 de mayo de 1994; 2) El 30 de septiembre de 1995; 3) El 28 de septiembre de 1996; 4) El 27 de septiembre de 1997; 5) El 26 de septiembre de 1998. Cada marcha era más masiva y encendida, hasta que se aprobó la ley en 1999, y se finaliza con la sexta jornada, en 1999 (Canales 2000, 76-77). Serán las últimas concentraciones públicas y multitudinarias, pues, ningún otro llamado ha concitado el interés evangélico por manifestarse para alcanzar sus demandas.

Sin embargo, en las elecciones de 1999, comienzan a manifestarse los primeros desacuerdos entre líderes evangélicos en relación con los candidatos. Por tanto, ellos mismos inician el proceso de convencer a la feligresía evangélica sobre por quién votar y por quién no. Entre los motivos, se argumentaba que Joaquín Lavín "pertenece al Opus Dei, al que calificaron como el grupo más antievangélico". Finalmente, 115 pastores y laicos evangélicos firmaron una declaración en la cual llamaban a sus fieles a votar por Ricardo Lagos (La Tercera 2000, 20). Uno de los adherentes, el obispo Emiliano Soto, presidente del Consejo de Unidades Pastorales de la Santiago, explicó que no se trata de una declaración política, sino pastoral, ya que les interesa apoyar al candidato que favorezca más a sus iglesias. Esto aunque Ricardo Lagos fue claro al expresar que es una persona agnóstica, aunque ha tenido tolerancia con los evangélicos. Mientras que el obispo y ex precandidato presidencial, Salvador Pino, reiteró su respaldo a Joaquín Lavín y señaló: "nuestro enemigo no es la Iglesia. Tenemos un enemigo común que es el relativismo moral, sostuvo Pino, agregando que apoya a Lavín debido a que comparte sus planteamientos valóricos y sociales" (El Mercurio 1999, D6).

A pesar de estas expresiones, el obispo Francisco Anabalón, presidente del Comité de Organizaciones Evangélicas (COE), manifestó que sólo Ricardo Lagos le ha enviado directamente cartas en que se compromete a elaborar un reglamento que cumpla con la Ley de Culto. Anabalón afirmó que el COE no recomendará a sus fieles votar por ningún candidato en particular, pero dijo que cada uno tiene que decidir quién garantiza el derecho de su iglesia, en vez de considerar razones políticas o económicas. Cabe recordar que el fallecido obispo Anabalón fue reconocido durante la dictadura militar por sus 
constantes apariciones en los púlpitos de los Te Deum evangélicos donde participaba el dictador Augusto Pinochet. Pero sus prédicas eran más ecuánimes frente a los pastores filopinochetistas como Javier Vásquez. De este modo, las indicaciones de Anabalón, al ser un líder religioso respetado entre los pastores, eran seguidas. Eran respetadas porque no era filopinochetista y porque sus prédicas durante la dictadura, si bien no eran críticas al régimen, hacían un llamado a la reconciliación. Además, pese a ser crítico de la izquierda, no la demonizaba ni promovía su persecución política.

En enero del año 2000, un grupo de 120 obispos y pastores evangélicos a nivel nacional publicó una declaración "Evangélicos por Lagos" en el diario La Tercera adhiriendo al candidato Ricardo Lagos, pero reivindicando el derecho que asistía a quienes disentían y votaban por Lavín. Esta participación produjo un giro definitivo en la perspectiva que hasta ese momento se tenía en Chile del pueblo evangélico. Es decir, los evangélicos votaron por un agnóstico y no por un creyente (La Tercera 2000,20 ).

Por otro lado, los pastores en conjunto e interdenominacionalmente llamaron a votar por un candidato político. Esto nunca había ocurrido en la historia evangélica de tradición pentecostal, solo había memoria de grupos minoritarios de pastores que llamaban a votar por un determinado candidato, pero nunca una agrupación interdenominacional de pastores, más aún por un candidato de izquierda. Por tanto, Pinochet no logró su cometido de despolitización o derechización del mundo evangélico, tal como se presumía.

\section{Conflictos políticos entre líderes evangélicos metropolitanos}

En el año 2000, se suscitó un conflicto donde se dieron dos Te Deum evangélicos. El entonces presidente de la república, Ricardo Lagos, decidió no asistir a la tradicional ceremonia de la Iglesia Metodista Pentecostal de Chile (IMPCH) y sí lo hizo en otro templo en Curicó, perteneciente a la Iglesia Pentecostal de Chile (IPCH). De esta manera, se rompió una tradición que se mantenía desde 1975. ¿Por qué el presidente fue aconsejado a asistir a la IPCH y no la IMPCH? Porque la IPCH fue fundada el año 1947 por el pastor Enrique Chávez Campos, cuyo templo central se encuentra en la ciudad de Curicó. La Iglesia Pentecostal de Chile, junto a la Misión Iglesia Pentecostal, fueron las primeras iglesias pentecostales en hacerse miembros activos del Consejo Mundial de Iglesias (CMI) desde la Asamblea General de Nueva Delhi, 1961. Por tanto, se constituyeron en un pentecostalismo ecuménico y, además, pertenecen al Consejo Latinoamericano de Iglesias (CLAI) desde su fundación en Lima en 1981. De igual modo, el obispo Chávez fue opositor al dictador Pinochet, pese a brindar su apoyo inicial el 13 de diciembre de 1974. Sin embargo, en agosto del año 1986, su iglesia encabeza una carta de repudio al Gobierno de Pinochet. Por tal razón, para los asesores evangélicos de Ricardo Lagos y para el mismo presidente fue emblemático asistir a un Te 
Deum evangélico a una iglesia pentecostal ecuménica, progresista y en permanente compromiso con una política que trasciende lo confesional.

Fue tanta la controversia, que al año siguiente el presidente Lagos tuvo que asistir al acto religioso en la Catedral Evangélica de Santiago (El Libero 2017), también conocido históricamente como el templo de Jotabeche. El presidente del Senado, Andrés Zaldívar, restó relevancia a la determinación del jefe de Estado, pues el mandatario ya había asistido a otro oficio religioso evangélico en el cual señaló:

Yo no le daría mayor importancia, creo que lo importante es la unidad, todos estamos detrás de lo mismo, el mundo evangélico es muy importante dentro de lo que es la sociedad chilena y los temas de ellos son propios de ellos (Emol 2000, 1).

Esto muestra que el tradicional Te Deum evangélico no genera unidad entre los líderes de esas iglesias, ya que no se le considera ni interdenominacional ni a favor de todos los evangélicos, sino sólo a los dueños de casa, quienes son los únicos que reciben beneficios.

En el contexto del año 2001, la Sociedad Bíblica Chilena le solicitó al presidente Ricardo Lagos la instauración del Día Nacional de La Biblia (El Mercurio 2001), cuya fecha propuesta era para el primer domingo de septiembre. ${ }^{2}$ 2. El mundo hispano celebra el Aunque la medida no se logró, sí fue el preámbulo para que, el 31 de octubre mes de la Biblia en septiembre, de 2008, la presidenta Michelle Bachelet promulgara (Día de la Reforma Pro- relacionados con la traducción. testante) como el Día Nacional de las Iglesias Evangélicas y Protestantes. Por un lado, el 30 de septiembre se conmemora el Paradójicamente, en los gobiernos de centro izquierda, es en los cuales los Día de Jerónimo de Estridón, evangélicos chilenos alcanzan mayor reconocimiento y visibilidad. Al respec- quien fue el traductor de la to, mencionamos otros acontecimientos en esta dirección, a saber: a) Desde Vulgata Latina. En segundo el año 2007, el Congreso Nacional conmemora y brinda tributo a las iglesias lugar, la primera Biblia evangélicas chilenas; b) En distintas ciudades de Chile, encontramos monoli- imprimió en septiembre de tos dedicados a la Biblia o a los diez mandamientos; c) En diferentes urbes, 1569. Se le llama la "Biblia del los gobiernos res con nombres de pastores por Cipriano de Valera en 1602 reconocidos por la comunidad; d) En múltiples ciudades o pueblos del país, y le da vida a la traducción de los municipios han reconocido a destacados pastores como hijos llustres de la ciudad. la Biblia más usada por las iglesias evangélicas de habla hispana: la Biblia Reina Valera.

Luego, durante el 2005, contexto de una nueva campaña política que nuevamente favorecía a la centro-izquierda, según un estudio del Centro de Estudios Públicos hecho por Arturo Fontaine y Harald Beyer:

Un 22,4 por ciento de quienes se declaran de centro son evangélicos. De quienes se dicen de derecha, un 11,1 por ciento se declara evangélico. De quienes se identifican con la izquierda, un 8,3 por ciento es evangélico. De los 
que se definen como independientes, los evangélicos son un 17,8 por ciento. Pero a pesar de la heterogeneidad de sus posturas, ya nadie duda de que son un nuevo poder (Fontaine y Beyer 1991, 35-36).

Así como en 1999, Ricardo Lagos inició una fuerte campaña en el mundo evangélico durante los últimos días de diciembre y hasta consiguió el apoyo público de varios pastores; en el 2005, la candidata a presidenta Michelle Bachelet selló varios compromisos con ellos (El Mercurio 2009). Durante el Gobierno de Michelle Bachelet, la pastora metodista Juana Albornoz, militante del Partido Socialista desde los 12 años, fue nombrada capellana de la Casa de Gobierno.

Esta vez no les sería fácil a los evangélicos que apoyaban a la candidata Michelle Bachelet porque, con el lema "Con Lavín: Alas para ti, hermano", el candidato presidencial de la UDI, Joaquín Lavín, estableció diez compromisos con el mundo evangélico, y aseguró que si es elegido presidente, se preocuparía de que la ley de culto no se quedara en el papel y velaría para que haya capellanías evangélicas en las Fuerzas Armadas y en las instituciones en las cuales miembros de esta comunidad lo requieran. También, Lavín planteó que impulsará clases de religión evangélica en los colegios municipales y que los estudios de los institutos bíblicos fueran reconocidos por el Estado (El Mercurio 2005). Aunque la ley de capellanía era una promesa de ambos, en el contexto de la ley de libertad religiosa del año 1999, con la promulgación del Decreto 155 del Ministerio de Defensa Nacional del 27 de mayo de 2008, se reglamenta la asistencia religiosa en establecimientos de las Fuerzas Armadas y de Orden y Seguridad Públicas. Así los uniformados, funcionarios y pacientes recibieron atención espiritual de parte de sus pastores. No obstante, tal como lo hicieran ver el diputado de la Democracia Cristiana Sergio Ojeda y el entonces capellán nacional evangélico del Ejército, doctor Jorge Cárdenas Brito, en el 2013, expusieron algo que hasta hoy, no se ha solucionado:

Un capellán católico tiene grado de capitán y gana la remuneración equivalente, gozando de previsión y de viáticos e incluso jubila a los treinta años de servicio, por lo cual recibe una pensión de por vida. En cambio, un pastor acreditado trabaja ad honorem y ni siquiera se le permite usar el nombre de capellán, por lo que no hay capellanía para ellos, por tanto, hay capellán sin capellanía (Emol 2013, 1). 
Como ha ocurrido en la víspera de otros procesos electorales, el voto de los evangélicos adquiere relevancia para los candidatos, y sus comandos despliegan gestiones encaminadas a conquistar la adhesión de los militantes de distintas denominaciones evangélicas. En ese marco, se destaca la iniciativa de un sector de seguidores evangélico que formó el movimiento político Reforma Cristiana, que convocó un encuentro nacional para adoptar una decisión sobre la segunda vuelta presidencial.

El presidente de dicha organización, Mario Muñoz, gestionó con representantes de los comandos de Michelle Bachelet y Sebastián Piñera para transmitirles sus aspiraciones y evaluar apoyos si aquellas eran recogidas. Muñoz señaló que Reforma Cristiana tiene presencia a lo largo de todo Chile y estaba en capacidad de movilizar unos 600000 votos de militantes evangélicos si se define el respaldo a una determinada candidatura. El religioso, diácono de la Iglesia calvinista, explicó que, entre los elementos esenciales que le interesan a Reforma Cristiana, se cuentan la garantía de un Estado neutral en lo religioso, que tenga una activa política social y que abra canales de participación política (de gobierno) a la gente del mundo protestante. Sin embargo, Bachelet se había reunido el 12 de octubre del 2005 en un desayuno en el Hotel Sheraton con 150 dirigentes y líderes evangélicos, donde no se explicitaron compromisos políticos específicos entre las partes.

Reforma Cristiana sería el segundo intento por articular una organización política que buscara representar al mundo evangélico, pues, una experiencia similar se vivió en la década de 1990 con el impulso de la Alianza Nacional Cristiana, que dirigía Abraham Larrondo; no obstante, una variedad de iglesias se agrupó en torno a tres entidades representativas del mundo evangélico: la Unión de Iglesias Evangélicas de Chile (UNIECH), el Comité de Organizaciones Evangélicas (COE) y el Consejo de las Unidades Pastorales de la Región Metropolitana (CUPREM) (EI Mercurio 2005).

En relación con las elecciones alcaldicias, el obispo Emiliano Soto, vinculado a los gobiernos de centroizquierda, señalaba por el año 2008 que:

Casi 200 hermanos nuestros están postulando a ser alcaldes, concejales en diversos municipios de Chile. Esto en forma transversal. Hermanos nuestros que tienen vocación de servicio. Es tiempo de que la Iglesia evangélica vaya asumiendo esta realidad; nosotros estamos en la línea de fortalecer el fenómeno evangélico (El Mercurio 2008, D23). 


\section{Politización del mito de la libertad de conciencia}

\begin{abstract}
3. UNE-CHILE o Mesa Ampliada es un conjunto de representantes de diversas organizaciones y denominaciones evangélicas que se unen con el objetivo de potenciar los valores y la cultura evangélico-protestante y darlos a conocer a la sociedad.

4. Con el concepto de ideología del ombliguismo, nos referimos a la permanente oposición de las iglesias cristianas, en particular de las evangélicas, sobre los proyectos de Estado en relación con las libertades sociales, como ley de aborto, ley de diversidad sexual, ley identidad de género, etc. En especial, esta última a la cual peyorativamente llama ideología de género.
\end{abstract}

5. Al respecto se puede ver el capítulo dos: "La política del apoliticismo", 45-72. De Evangélicos y política en Chile 1960-1990 Política, apoliticismo y antipolítica. Miguel Mansilla y Luis Orelana, RIL.UNAP, Santiago
Por otro lado, en las elecciones del año 2009, hubo una cercana competencia entre los candidatos: Eduardo Frei, Marco Enríquez-Ominami y Sebastián Piñera. En sus giras por el territorio, activaron fuertes campañas para captar el voto evangélico. "Según cifras de la encuesta CEP (Centro de Estudios Públicos), un $17 \%$ de los inscritos son evangélicos. De ellos, $34,5 \%$ tienen como intención dar su voto a Frei; $32,7 \%$ a Piñera y 15,2\% a Enríquez-Ominami" (El Mostrador, noviembre 29 de 2009, citado por Archivo Chile). El presidente de la Mesa Ampliada de Entidades Evangélicas y Protestantes de CHILE (UNE-CHILE), ${ }^{3}$ obispo Emiliano Soto, "explicó que al interior del credo se instaló una fuerte molestia por el tratamiento de los temas valóricos en las franjas presidenciales, en especial por la inclusión de gestos a los homosexuales por los candidatos de centro izquierda" (El Mostrador 2009, citado en Archivo Chile). En estas elecciones, lentamente va apareciendo la preocupación de los evangélicos, que aquí llamaremos como la agenda del ombliguismo. ${ }^{4}$

Las elecciones del año 2009 fueron los primeros comicios más acalorados y con mediáticos enfrentamientos entre líderes evangélicos. El presidente de la (UNE-CHILE), el obispo Emiliano Soto, llamó a votar por Eduardo Frei. Para él, este era el único que representaba el continuismo del Gobierno de la presidenta Michelle Bachelet. En esta discusión, ocurrió aparentemente una lucha entre líderes evangélicos apoliticistas y partidistas. ${ }^{5}$ Ante el llamado del obispo Soto, el más acérrimo crítico fue el pastor y conferencista David Hormachea, quien al respecto expresa:

Debido a que todo dirigente evangélico tiene derecho a decir a quien apoya personalmente, debemos respetar sus opiniones. Ninguna organización evangélica representa el pensamiento de todos los evangélicos. Ningún dirigente de una organización evangélica que representa a grupos de evangélicos de diversas congregaciones tiene el derecho de promover a candidatos, debemos condenar la promoción en forma específica a candidatos y organizaciones políticas, especialmente la promoción de las filosofías políticas agnósticas y secularistas progresivos que promueven el ateísmo y el humanismo. Nuestro voto no debe basarse en los compromisos que hacen los dirigentes evangélicos y dirigentes políticos. Los sindica- 
tos hacen negociaciones y acuerdan su voto, no los ciudadanos del reino de Dios (Hormachea 2010, 6).

Otra declaración destaca:

Ninguna persona u organización, vinculada o no a la Iglesia Evangélica Chilena, puede atribuirse la representación de los evangélicos de Chile y mucho menos llamar a votar nulo. La Iglesia Evangélica Chilena entiende que cada persona es legalmente libre en nuestro país para decidir o proceder de acuerdo a su conciencia y a su soberana voluntad. Al ejercer su legítimo derecho a sufragio por lo que reconocemos que el voto es un acto secreto, libre informando y sin presión alguna. De la misma manera, no corresponde a la Iglesia asumir posiciones respecto de los diversos planteamientos de quienes postulan a la Presidencia de la Nación (Prensa Evangélica 2010, 8).

De igual modo, Eduardo Durán, pastor principal de la Iglesia metodista pentecostal Jotabeche, señaló: "No estamos comprometidos con nadie. Todos tenemos nuestras particulares opciones, pero no debemos hacer llamados públicos a adherir a ninguna candidatura. Nos preocupa la inconsecuencia del obispo Soto" (Prensa Evangélica enero de 2010, 8). Hasta aquí, podría ser una postura brillante porque defendería el laicismo, la separación Iglesia-Estado y la libertad de conciencia. Sin embargo, no es así, por dos motivos. Primero, porque en realidad lo que había detrás de toda esta parafernalia comunicativa no era la defensa de la libertad de conciencia, sino más bien la unificación derechista de los líderes evangélicos que pretendían apoyar, pero de manera sigilosa, a Piñera, porque aunque los presidentes Frei, Lagos y Bachelet hicieron grandes aportes a la religión evangélica que beneficiaron a todos, los líderes que apoyaron a Piñera buscaban beneficios para sus propias iglesias y posicionamiento personal en el Gobierno, sobre todo para el pastor

Durán, de sus familiares y líderes cercanos, ya fuera un cargo de confianza ${ }^{6 .}$ Los evangélicos han en el Gobierno o un cupo en el Congreso.

oportunidades tener un candidato a presidente de la

República 1937, 1970 y 1999;

Dado que los evangélicos son conscientes de su imposibilidad, ni siquiera como candidato a presidente ${ }^{6}$ entonces la negociación se orienta a la lenta conformación de una bancada evangélica de derecha. Los líderes evangélicos conservadores no estaban acostumbrados a realizar llamados públicos para que los creyentes votaran por un determinado candidato. Tradicionalmente, lo han hecho a través del mecanismo "un pastor llama a otro", y de y entre el año 2016 y 2017

hubo intentos de levantar una precandidatura a

presidenciable pero no se logra porque se trata de un

candidato confesional y no transversal. 
ahí sugerir, desde el púlpito, de manera solapada, por qué candidato votar. De este modo mantener el mito de la libre conciencia.

Segundo, el pastor Hormachea manifiesta su molestia, por un lado, porque el obispo Emiliano Soto se le adelantó en la declaración; y por otro, porque Soto hizo pública una declaración que Hormachea y los otros pastores hacían en un acuerdo secreto. Así, como veremos más adelante, el pastor Hormachea, en el año 2017 hará lo mismo que él tanto criticó al Pastor Soto en la elección de 2009. Por lo tanto, no es la libertad de conciencia lo que le interesa, sino la cautivación de la conciencia política de los evangélicos, por un lado; y la derechización de esa conciencia evangélica, por otro, lo que preocupa al pastor Hormachea y a los líderes religiosos que le siguen.

A esta polémica también se unieron pastores de la zona sur de Chile: "Escojamos con libertad de conciencia al próximo presidente que tenga un aporte ético y una moral respetable, señaló Carlos Martínez González presidente Unión de Pastores Provincia Osorno" (Prensa Evangélica, enero de 2010, 8). De igual modo, participó en la discusión el obispo Hédito Espinoza, presidente de las Unidades Pastorales, quien "destacó que el Pastor Soto, divide al cuerpo de Cristo y eso no es saludable" (Prensa Evangélica enero de 2010, 8). El pastor Rodolfo Campos Porflitt, director del periódico Prensa Evangélica, señaló:

Como evangélicos tenemos el legítimo derecho de tener nuestras preferencias; a entrevistarnos con todos los candidatos; a escuchar sus propuestas y dar a conocer nuestras inquietudes, pero de allí a llamar a los evangélicos a optar por una candidatura determinada, por decir lo menos, es una acción carente de sabiduría (Prensa Evangélica 2010, 9).

Sin embargo, la división política entre los evangélicos ya era una realidad manifiesta, profunda e irreversible. No obstante, un sector de líderes evangélicos seguirá apoyando a la candidata, expresidente Michel Bachellet: "para nosotros el apoyo se inició 10 años atrás. Confiamos en la continuidad del Gobierno de la presidenta Michelle Bachelet, y para nosotros el continuador en todas las reivindicaciones del mundo evangélico es Eduardo Frei" (Emol 2010, 1).

En la campaña de 2013, los candidatos a la presidencia; en este caso, Michelle Bachelet y Evelyn Matthei, se vuelven al mundo evangélico en búsqueda de adeptos. Una de las candidatas que más busca el apoyo evangélico fue la abanderada de la derecha Evelyn Matthei, quien fue más allá del habitual apoyo político: "en mi gobierno no voy a hacer nada que vaya en contra de lo que la Biblia establece... Al otro lado, más de tres mil fieles le dieron un cerrado aplauso cuando la presidenciable reiteró el mensaje de su agenda 
valórica" (Emol noviembre 25 de 2013, 1). De este modo la desesperación política de la candidata Matthei entra al juego discursivo de los evangélicos conservadores. Frente a ello señala: "el matrimonio es entre un hombre y una mujer. La vida se cuida desde el momento de la concepción hasta el momento de la muerte natural. Nosotros, le decimos no al aborto y no a la eutanasia" (Emol noviembre 25 de 2013,1). De este modo, Matthei se vuelve correspondiente con el discurso evangélico de la ideología del ombliguismo y, con este discurso, no sólo intenta ganar el favor evangélico, sino también una crítica abierta a la candidata y expresidenta Michelle Bachelet. Así Matthei se dejaba acompañar por el senador electo y converso evangélico de la UDI, Iván Moreira, quien cuando ganó dijo: "soy el primer parlamentario evangélico que llega a la Cámara Alta" (Emol 2013, 1). Como vimos, Moreira ignora o desconoce totalmente la historia de los evangélicos y la política en Chile.

Otro líder político que ha buscado la venia y el apoyo evangélico ha sido Franco Parisi, quien es apoyado por distintos pequeños partidos y agrupaciones evangélicas, tales como Unidos por la Fe, ${ }^{7}$ Democracia Regional, Anticorrupción y Poder de la Gente, Instituto Progresa, el Movimiento Chile te Cuida y el Sindicato Nacional de Trabajadores, patrocinaron la nominación del eco-

7. Ver en http://www.unidosenlafe.cl/unlaf e/ nomista y panelista de televisión.

Parisi, tuvo una reunión con 70 líderes evangélicos de diversas iglesias a principio del mes de febrero. Realizó esa convocatoria, ha escuchado a sectores evangélicos $\mathrm{y}$, si fuese candidato, tiene el interés real de integrar al mundo evangélico a un eventual gobierno, cosa que no ha hecho ningún candidato (Barrios 2017, 1).

De seguro Parisi no volverá a ser candidato a presidente, pero sí candidato a senador, y lo hará buscando el apoyo de los evangélicos, pero sin éxito.

Entre tanto, otro pastor evangélico que se ha hecho conocido por su virulencia homofóbica ha sido el pastor Javier Soto, quien invadió el congreso cuando estos legislaban sobre un proyecto de derechos vinculado a la diversidad sexual (MOVHIL) y, además, tal actuar irreverente frente a las autoridades democráticas fue avalado por otros conocidos pastores, entre ellos: Hédito Espinoza. MOVHIL y los sectores evangélicos están permanentemente en constante luchas de declaraciones cruzadas de inmoralidad e intolerancia. Esta organización, incluso, va más allá y acusa a los evangélicos de promover un discurso del odio. Como señala Ignacio Cid:

[...] la relación del evangélico con la política es clientelar, adquiriendo la forma de un consumidor que protege con virulencia sus intereses cuando estos están en juego. De alguna manera, el evangélico tendería a relacionarse con 
la política a través de esta tensión mercantil que encuentra su resolución en la violencia física o simbólica como forma última de expresión- (Cid 2015, 1).

En los contextos de elecciones, estas luchas entre minorías sexuales y minorías religiosas son alimentadas por candidatos de tendencia conservadora que buscan redituar votos. Al respecto, la candidata derechista Evelyn Mathei, en su desesperación por aglutinar votos o más bien para no perder con tanta diferencia, se reunió con pastores evangélicos criticando las propuestas de la entonces candidata Michelle Bachelet y sostuvo que:

Hay una amenaza fuerte de tener a Dios como centro de la vida, tratando de negar esto como ocurrió en los países socialistas durante tanto tiempo... las palabras de la exministra terminaron echando por tierra su reconocida trayectoria liberal y convenciendo a quienes dudaban, de que la elección presidencial está perdida, porque pedir el voto evangélico, o de cualquier otro grupo religioso, significa que ella está renunciando a sus convicciones para la segunda vuelta (Rivas 2013, 1).

Como destaca Daniel Lowe, para Matthei:

No se hará nada que vaya en contra de lo que la Biblia señala: el matrimonio es entre un hombre y una mujer y la vida se cuida desde el momento de la concepción hasta la muerte natural. No al aborto, no a la eutanasia (Loewe 2013, 1).

La búsqueda del voto evangélico por parte de los candidatos siempre ha sido complejo porque se trata de una realidad liada y ambigua, pues en este sector:

No funcionan precisamente los tradicionales tres tercios de la sociedad chilena. Podríamos afirmar de una forma sencilla que dos cuartos votan por las ideas laicas, liberales y de centro-izquierda, en razón a su asociación histórica con las tendencias social demócratas, mayormente 
de extracción popular. Otro cuarto vota por la derecha, debido a sensibilidades sociales, y el otro cuarto es vacilante (Fonseca 2013, 1).

Pese al hostigamiento por parte de la candidata de la derecha política a su adversaria en la carrera presidencial Michelle Bachelet, la UNE-CHILE formalizó su respaldo a la candidatura presidencial al pacto de Bachelet. Emiliano Soto aseguró que Bachelet era la abanderada que mejor representaba los intereses de la Iglesia evangélica. No obstante, la ideología del ombliguismo, no es sólo de interés de los líderes evangélicos conservadores, sino también de los progresistas, como el obispo Soto: "las iglesias evangélicas a la interrupción del embarazo en todo tipo de situaciones. Por tanto, rechazan categóricamente el aborto, la eutanasia y la discriminación. La opción siempre ha sido es a favor de la vida". A pesar de ello, defiende la reforma educacional y afirma: "soñamos con un Chile donde exista una educación gratuita, de calidad e inclusiva" (Emol 2015).

Un acontecimiento significativo ocurrió en septiembre de 2013 cuando se cumplieron 40 años del golpe militar, en el cual los líderes evangélicos apoyaron al dictador Pinochet con una carta el 13 de diciembre de 1974. El pastor Durán de la Catedral Evangélica, popularmente conocido como Jotabeche, señala:

Pido perdón (...) a los chilenos que vieron una vez más la peor cara de la iglesia. Me parece vergonzoso que la agenda valórica sea lo único que escuchamos de pastores que debieran predicar el amor de Dios. ¿Acaso el Estado les obliga a abortar? No. ¿Acaso el Estado les obliga a contraer matrimonio homosexual? No. ${ }^{8}$

8. Radio Bio-Bio Chile, «Iglesia y Estado: La carta del pastor luterano que pide perdón tras

No obstante, esta mea culpa fue tardía y fría, pues vino de la intervención del críticas en Te Deum». obispo Eduardo Durán, dueño de la casa que albergó y legitimó el accionar de la dictadura militar; fue, más bien, un acto formal antes de profunda contrición. ${ }^{9}$
9. Ver

https://www.youtube.com/watch $? \mathrm{v}=\mathrm{Q}$ coamlnODPU

\section{Politización del mito fundacional evangélico Chile para Cristo}

Por otro lado, los evangélicos vuelven a construir una articulación para fundar partidos políticos confesionales, pero esta vez es en regiones del país: Partido Nuevo Tiempo (Antofagasta); el Partido Unidad Cristiana Nacional (Araucanía); Partido Unidos en Fe, quien apoyó como candidato presidencial a 
10. Con el concepto de ideología del ombliguismo nos referimos a la permanente oposición de las iglesias cristianas; en particular, de las evangélicas, sobre los proyectos de Estado en relación con las libertades sociales como ley de aborto, ley de diversidad sexual, ley identidad de género, etc. En especial, esta última a la cual peyorativamente llama "ideología de género".
Franco Parisi; y el Partido Cristiano Ciudadano. En este último partido, levantaron su propio candidato presidencial: Abraham Larrondo, pero no juntaron las firmas suficientes para inscribir su postulación.

Dichos partidos intentan posicionarse cada uno como el referente político del mundo evangélico, cuya característica central y común es la ideología del ombliguismo. Esto es, validan la moral sexual conservadora como eje articulador, deslegitimizan cualquier posición que esté a favor de la despenalización del aborto, el matrimonio igualitario y la ley de identidad de género. Los cuatro partidos evangélicos apoyaran a líderes de derecha: Manuel Ossandon, José Antonio Kast, Sebastián Piñera, todos a favor de la ideología del ombliguismo. ${ }^{10}$ Indirectamente, apoyan las leyes antimigrantes, antieducación pública, antimedioambiente y cero preocupación por la salud y la reforma previsional.

La plataforma Un Chile para Cristo respaldó a 10 candidatos a diputados. En la Región Metropolitana (Santiago), compitieron: Angélica Pino, Eduardo Durán (hijo del obispo Duran), Eddy Roldán y Andrea Ojeda. Mientras que en las regiones, lo hicieron: Francesca Muñoz, Edgardo Sepúlveda, Freddy Araneda y Elías Ramos. Según sus cálculos, cuatro o cinco podrían ser electos. De ellos, la mitad son militantes de Renovación Nacional (RN), el resto independientes y uno de Amplitud. No obstante, un aspecto significativo que los grupos evangélicos hicieron fue construir una plataforma llamada: Por un Chile para Cristo en su sitio web consignan:

Un Chile para Cristo, es un movimiento cristiano evangélico, independiente, conformado por profesionales cristianos que promueve la REEDUCACIÓN CÍVICA, con el fin de procurar que los cristianos evangélicos, concurran a ejercer el derecho a sufragio, informada y libremente. Teniendo presente que nuestra elección sea por hombres y mujeres que fomenten los valores de una sociedad temerosa de Dios. Por un Chile para Cristo, Jamás señalará por qué candidato deben votar. Nuestro objetivo es reeducar a cristianos en cuanto a los principios y valores que debe representar el candidato al cual se le entregue vuestro voto. Elegir a un candidato al cual apoyar es un acto personal, pero es fundamental que al votar un cristiano conozca si su candidato representa sus creencias, sus valores y principios bíblicos en que funda su estilo de vida... si votamos con conocimiento y sabiduría cumplire- 
mos la hermosa promesa que Dios nos ha dado "CHILE

SERÁ PARA CRISTO" (Por un Chile para Cristo 2016). ${ }^{11}$

También, hay otros conglomerados donde participan evangélicos, por ejemplo, en Amplitud, están Alejandro Tello y Leonardo Contreras; en Evópoli, Elías Vistoso y René Núñez; en UDI, Érika Muñoz y Kurt Horta; en RN, Macarena Donoso; y en el Frente Amplio, Irma Pérez. Pese a esta diversidad, los evangélicos más interesados de participar en elecciones son de derecha porque, de algún modo, tanto los medios de comunicación como los mismos líderes evangélicos se han encargado de desacreditar a los partidos de centro izquierda como entes "antivalóricos", sin importar si estos conglomerados apuestan por valores sociales: educación, salud, derechos laborales y previsión. Para los evangélicos conservadores, eso no importa, sólo importa la ideología del ombliguismo. Así, la plataforma Chile para Cristo dio resultados, porque, finalmente, fueron tres los diputados evangélicos elegidos: Eduardo Durán, (Santiago) Francesca Muñoz y Leónidas Romero (Concepción), autodenominados bancada evangélica. También, aparece en la página el excandidato Edy Roldán, Seremi de Transportes en la Región Metropolitana (Santiago).

En cuanto a la campaña, alcaldicia del año 2016, fueron ocho los candidatos evangélicos que buscaron la representación popular ese año, además de 35 a concejal en regiones; y 31, en la Región Metropolitana. Alrededor de quince fueron a la reelección. Los candidatos, que recibieron capacitaciones en educación cívica, eran de distintos partidos (El Mercurio, septiembre 18 de 2016). Finalmente, lograron elegir cinco alcaldes (de un total de 345) y 24 concejales (de un total de 2240). Entre ellos, Henry Campos (34 años), alcalde UDI de Talcahuano; Daniel Agusto (38 años), de Calama por RN; Aldo Pinuer en la Unión, por la UDI; Jorge Rivera en Purén, por el PPD (centro izquierda).

Durante las elecciones presidenciales del año 2017, uno de los candidatos más refractario a vincularse a los evangélicos por sus nexos con el Partido Radical, Alejandro Guillier, acudió. Pese a ello, sumó pastores evangélicos a su campaña. Estos líderes evangélicos eran pastores emblemáticos, como la pastora Juana Albornoz y el pastor Juan Godoy, y buscaban equiparar el apoyo que parte del sector ha mostrado al candidato Sebastián Piñera ( $L a \mathrm{Na}$ ción, septiembre 18 de 2017). Durante el año 2017, ocurrieron dos fenómenos inauditos en la relación evangélicos y política en Chile:

En primer lugar, el pastor David Hormachea, en el año 2009, rasgó sus vestiduras cuando el pastor Emiliano Soto llamó a los evangélicos a votar por Frei, en gratitud por la ley de igualdad de culto que había promulgado en el año 1999 cuando era presidente de la república. Sin embargo, Hormachea critica a Soto porque sucumbía la libertad de conciencia de cada creyente; pero en julio del año 2017, él motivó a los ciudadanos a votar por Manuel Ossandon, en una declaración cuasiecuménica titulada "Evangélicos y católicos chilenos: voten a favor de la moral bíblica en las primarias". En esta oca-
11. Ver en

https://www.porunchileparacristo. $\mathrm{com} /$ 
sión, expone un decálogo de nueve puntos del por qué votar por Manuel Ossandon:

Les recomiendo que voten por el señor Manuel José Ossandón en las elecciones primarias. Por las siguientes razones: 1) Que tenga una historia de profesionalismo, una carrera ascendente, caracterizada por responsabilidad, integridad y logros reconocidos; 2) Que no sea ateo, agnóstico ni sea un liberal en su moralidad; 3) Que esté a favor de la vida, que rechace el aborto y la eutanasia. Que ayude a mujeres con embarazos vulnerables en vez de que aborten; 4) Que crea que la sociedad se construye sobre la base de la familia y que allí se deben transmitir los valores y virtudes ciudadanas: 5) Que promueva que los padres, y no el Estado, son los que tienen derecho y obligación de enseñar la moralidad que ellos elijan y no la que el estado imponga; 6) Que tenga el compromiso de fortalecer la verdad sobre el matrimonio como la base principal de la familia y como la unión de un hombre y una mujer; 7) Que luche para que los niños sean protegidos y amados y que puedan ser adoptados por matrimonios de un hombre y una mujer saludables y lo más rápido y sabiamente posible; 8) Una persona que tome en cuenta las organizaciones católicas y evangélicas para que tomen un rol importante en la enseñanza valórica y la ayuda social en cárceles, casas para mujeres maltratadas, orfanatos, y que reconozca el aporte evangélico en la sociedad y abra las puertas para la ayuda social (Hormachea 2017, 1).

Hormachea comienza apoyando a Ossandon. Cuando Ossandon pierde las primarias y siguen en carrera J. A. Kast y Piñera para las presidenciales, Ilama a apoyar a Kast; y cuando Kast pierde y sigue Piñera, llamó a votar por Piñera. El pastor, en su desconocido ecumenismo, convoca a católicos y evangélicos a votar por candidatos de la derecha, pese a que los tres perte- 
necen a la oligarquía católica, conocida por su postura antievangélica y pentecosfóbica. Por lo tanto, aquí ocurren dos fenómenos: a) Un pastor que vive fuera de Chile, expresamente en Estados Unidos, influye en elecciones presidenciales. Una vez más evangélicos y Estados Unidos confluyen en su odiosidad a la izquierda chilena, como se inició en la década de 1960, y b) No obstante, lo inaudito fue su explícito cuasiecumenismo, algo que los evangélicos chilenos siempre han rechazado. De hecho, es más profundo el antiizquierdismo que el antiecumenismo por parte de Hormachea y los distintos líderes evangélicos pronorteamericanos.

Otro de los acontecimientos desafortunados sucedió durante en el Te Deum Evangélico, en septiembre del 2017, cuando el actual diputado Durán, entonces laico y candidato al parlamento en su intervención, dio una prédica marcada por la irreverencia hacia la entonces presidenta Michelle Bachelet. La ceremonia religiosa partió, con cánticos y gritos, que recibió la mandataria en un clima de hostilidad inusitada, en las puertas del templo Jotabeche, con expresiones como "asesina", "vergüenza nacional" y otros insultos lanzados de forma irreverente. Por el contrario, los aplausos de reconocimiento, para el entonces candidato a presidente de la república, Sebastián Piñera, fueron evidentes, en señal de una mayor afinidad con los valores de su posible gobierno en comparación con el vigente. Contradictoriamente, la presidenta fue recibida como un verdadero personaje maléfico. Esos gritos acusadores ya eran inauditos en un templo evangélico. A esto se sumó la alocución del predicador Eduardo Durán Salinas. ${ }^{12}$

12. Hijo del obispo Eduardo Durán Castro dueño de casa, a

Pero este réprobo acto no se trata sólo de una postura política y partidista, sino que declara un problema cultural: es un acto misógino y sexista. No hay crítica a ninguna otra autoridad presidencial, incluso ni a Piñera, cuando siensu vez candidato a diputado por RN, y exgobernador por la provincia de Ñuble durante el do presidente, a veces con sus negocios éticamente difusos. ¿Por qué ningún presidente ha sido conminado? Porque son hombres. En cambio, la presidenta Bachelet, por ser mujer, recibe este trato del predicador Durán Salinas, quien se arrogó una postura patriarcal de acusar a la presidenta, como cualquier otro hombre que se arroga esa autoridad, porque está en su casa.

Aquí el señor Durán Salina se sintió con la libertad y la autoridad para hacerlo, porque estaba en la casa-templo, pero además, estaba en el púlpito facilitado por su padre. En su doble condición de predicador y político, no reconocerá ni se disculpará por la ignominia a una autoridad de Estado, una mujer, una presidenta, porque tal como decía un dicho popular "las P" (predicador, político, Papa, etc.) no se equivocan. Por ello, no piden perdón. Ellos sólo le piden perdón a Dios y no a quien humillan o avergüenzan. Dado que el Te Deum Evangélico pasó de un acontecimiento religioso-político a uno religioso-partidista, de seguro que en el futuro las autoridades presidenciales que no sean partidista de tal Te Deum se abstraerán de asistir, excepto que se asegure el respeto a la investidura presidencial (Mansilla 2017a; Mansilla 2017b).

Otra particularidad de las elecciones del año 2017 fue el retorno permanente de los evangélicos a construir partidos confesionales: 
Según el reportaje del medio evangélico Cosmovisión serían cuatro los nuevos partidos evangélicos: el Partido Nuevo Tiempo, ubicado en la zona norte principalmente en la región de Antofagasta; El Partido Unidad Cristiana Nacional en la región de la Araucanía; el Partido Unidos en Fe, que salió a la luz pública luego de levantar el apoyo como candidato presidencial a Franco Parisi; y el Partido Cristiano Ciudadano quienes habían levantado como su propio candidato presidencial a Abraham Larrondo, que tras diversos escándalos al interior del Partido no lograron juntar las firmas necesarias para inscribirlo frustrando su postulación (Jarpa 2017, 1).

En el caso de Partido Nuevo Tiempo, trabajaron por conformarse en Arica, Tarapacá, Antofagasta, Atacama y Coquimbo. Es liderado por el ingeniero Josué Cortés. El Partido Unidad Cristiana Nacional aún no se constituye, pero buscaría conformarse en La Araucanía, Los Ríos y Los Lagos. Lo encabeza el abogado Edgardo Sepúlveda. El Partido Unidos en Fe se está conformando en la zona centro del país, Santiago, Valparaíso y O'Higgins. Es liderado por el pastor Danny Molina y apoyará como candidato presidencial a Franco Parisi. El Partido Cristiano Ciudadano también apunta a conformarse en Santiago, Valparaíso y O'Higgins. Es dirigido por el cientista político Abraham Larrondo, quien además fue su candidato presidencial.

También durante al año 2017, el sector encabezado por el obispo Durán creó una nueva organización para agrupar iglesias: el Concilio Nacional de Iglesias Evangélicas (CONIEV). De esta forma, hasta hoy, existen tres grandes conglomerados que representan al mundo evangélico. Estas instancias de unidad son: UNE-CHILE o Mesa Ampliada liderada por (Emiliano Soto); el Consejo Nacional (Jorge Méndez); y el CONIEV (Eduardo Durán). La alianza entre el Consejo y el CONIEV para apoyar al Gobierno de Piñera, siguió dando frutos: la plataforma política Por un Chile para Cristo, el paraguas que cobijó las 11 candidaturas parlamentarias en las elecciones parlamentarias de 2017. Esta iniciativa, fue dirigida por los hermanos "Alan y Eddy Roldán, además de Eduardo Durán Salinas, es la principal promotora de la bancada evangélica" (Ramírez y Pizarro 2017, 1). Según el director ejecutivo,

[...] sería obtener entre tres y cinco candidatos electos, para continuar el trabajo como bancada evangélica... y en las próximas parlamentarias ampliar su presencia con candidatos al Senado, hasta alcanzar el objetivo final: 
presentar un candidato presidencial evangélico con reales posibilidades para el año 2038 (Ramírez y Pizarro $2017,1)$.

Hay un aspecto por destacar: el caso de los líderes evangélicos confesionales elegidos como presidentes de federaciones de estudiantes universitarios. Varios de esos líderes, hoy están participando como diputados, alcaldes o subsecretarios del Gobierno del presidente Piñera. Por ejemplo, Héctor Muñoz Uribe (actual concejal por Concepción y esposo de la diputada Francesca Muñoz, ambos de RN) ganó las elecciones en la Universidad de Concepción (FEC) el año 2004 y luego será reelegido; finalmente, el 2007 ayudará a conquistar la presidencia de la federación a un candidato de derecha. De igual modo, en Santiago, Rodrigo De La Calle ganó terreno en la Universidad Católica, al ser electo presidente de la FEUC. Mientras, Muñoz era de derecha, De La Calle era de izquierda; el primero bautista y el segundo pentecostal.

También, desde 2002, existe la Federación de Estudiantes Cristianos, dirigida por Edgardo Pizarro -estudiante de Administración Pública en la Universidad Academia de Humanismo Cristiano-, en la cual se aglutina parte importante de las agrupaciones cristianas evangélicas de las universidades nacionales (El Mercurio 2004, 18).

A ellos se suma Guillermo Allende, amigo de Muñoz, expresidente de la Federación de Estudiantes de la Universidad Católica de Temuco, quien fue candidato a diputado independiente por Temuco.

Aunque los casos anteriores son aislados, y pocas veces difíciles de identificar sus vínculos evangélicos, como sucedió el año 2017 con el presidente de la FEUSACH (Federación de Estudiantes de la Universidad de Santiago de Chile), Patricio Medina, quien también era de origen evangélico. Este generó una alianza entre Revolución Democrática -donde milita desde hace tres años-, el Frente de Estudiantes Libertarios (FEL), el Movimiento de Izquierda Revolucionaria (MIR), Convergencia de Izquierda y Acción, quienes derrotaron a sectores más de izquierda como las Juventudes Socialistas, Juventudes Comunistas e Izquierda Ciudadana. Además, se transformó en el primer presidente de federación en el ámbito universitario perteneciente a Revolución Democrática. ${ }^{13}$

13. Página de la Universidad de Santiago de Chile: marzo 16 de 2017.

http://www.usach.cl/news/nuevo -presidente-la-feusach-patrici o-medina-me-preocupa-peligre-a poyo-las-instituciones-0

La marcada bipolarización del mundo evangélico se hizo evidente en la campaña presidencial del año 2009. Desde el punto de vista externo, tiene que ver con los procesos de profundización democrática, en los cuales los derechos se extienden hacia las minorías sexuales y demandas del movimiento 
feminista. La lucha, legitimación y legalización de estos derechos, en este contexto, se transforma en el pretexto para que grupos evangélicos, vinculados a sectores de derecha, como señalamos anteriormente, ya no busquen el apoyo extra eclesiástico de líderes políticos, sino que pretenden situarse ellos mismos como candidatos a través de elecciones municipales, diputados y senatoriales, con miras a disponer de un presidente de la república evangélico en las próximas décadas.

Ese giro también se relaciona con la movilidad social de los creyentes y de los líderes pastorales que, dada las mejoras socioeconómicas, el anhelo premilenario del siglo $\mathrm{XX}$ disminuye, lo cual produce que busquen integrarse social y políticamente en la sociedad chilena. También, hay una clara manifestación del centralismo chileno, que se traduce en un centralismo religioso. Vemos este fenómeno en la visibilidad que adquieren líderes evangélicos en Valparaíso, Santiago y Concepción, en detrimento de las otras regiones del norte y sur de Chile.

Esto manifiesta un notable cambio socioteológico y teológico-político a partir de una visión premilenarista a otra postmilenarista. Desde las primeras investigaciones (Lalive D’Epinay 1972) hasta las recientes (Mansilla 2016), el pentecostalismo ha sido descrito como premilenarista. El resto de los evangélicos como los metodistas y otros grupos pentecostales que hemos trabajado en otras investigaciones (Mansilla y Orellana 2018) se han integrado política y socialmente. Estos han aceptado las reglas de la diversidad social y del relativismo moral, y han entendido el rol de la religión más bien como una dimensión cooperadora de la política y del espacio público. En cambio, mientras:

la ideología pentecostal ha sido premilenarista, en tanto, los fieles creen que el regreso del Mesías precederá al reino, instaurándolo. $Y$ es dualista porque se basa en una separación tajante entre lo espiritual y lo material. En la cosmología pentecostal, esta dicotomía se expresa en términos de cielo y mundo, de la que fluye la oposición iglesia-sociedad (Lalive D’Epinay 1972, 104).

Se trata de una negación total de la historia como acontecimiento humano. Es la creencia religiosa del fin de la historia o una historia en la cual los grupos religiosos se mantienen al margen de lo político y reciben, con sumisión, las decisiones de las autoridades políticas. Por tanto, la historia se concibe como un acontecimiento lineal, un destino indubitable en el cual el ser humano no puede ni debe hacer nada por impedirlo. Lo único que puede hacer es convertirse religiosamente para impedir su destrucción personal y familiar.

Los grupos premilenaristas, apoyados en la espera inminente del reino, resiste difícilmente la prueba del tiempo. El Reino se hace esperar y no queda 
más remedio que instalarse en una provisionalidad que se prolonga. De esta manera, la expansión continua, la llegada permanente de conversos permite tolerar la espera y, así, seguir creyendo en la esperanza apocalíptica (Lalive D’Epinay 1983, 99). Rivère lo corroboró veinte años más tarde en el pentecostalismo indígena boliviano: "la espera mesiánica sigue siendo importante, pero se ha moderado: en lo sucesivo es necesario resolver problemas inmediatos y a menudo con la colaboración de los "paganos" (Rivíere 2004, 280).

El mundo evangélico chileno, liderado por los pentecostales, ven con anhelo y frustración la relación entre la política y los evangélicos, por ejemplo, como ocurre en Brasil donde la bancada evangélica es relevante y permanente, además del constante crecimiento del mundo evangélico en ese país. En cambio, en Chile, las encuestas muestran un estancamiento; es decir, existe sólo un crecimiento vegetativo y son irrelevantes en el ámbito de la política institucional para afectar los espacios públicos.

En ese sentido, el mundo evangélico, especialmente el pentecostal, se ha vuelto postmilenarista, en tanto la tesis escatológica que enseña que el regreso de Jesús a la tierra tendrá lugar al final del milenio, pero mientras tanto la Iglesia debe intervenir y afectar la sociedad política, social y culturalmente. Es una visión optimista-pesimista de la sociedad: optimista en cuanto considera el poder transformador del evangelio, no sólo en el plano espiritual e individual, sino también en el social, el político y el cultural; y pesimista, en cuanto a que la venida de Cristo se demora y, por tanto, aumenta el mal y se enfría la fe de muchos.

Lo significativo del postmilenarista, es que, a diferencia del premilenarismo, se dan dos grandes visiones: la pietista y la geonómica (Couch 1999, 368; Berkhof 1976, 857-859). Los primeros se autoconsideran los "calientes espirituales" y los otros son los "fríos espirituales". Los postmilenaristas pietistas consideran tener una doble lucha: una contra "los males de la sociedad" y contra los "malos de la iglesia". Desde su visión, estos "malos internos" se vuelven indiferentes y así el "mal" aumenta no sólo por el "poder del mal", sino también por la "indiferencia" de los "otros evangélicos".

Lo que une a ambos postmilenarismos es que, como evangélicos, deben ejercer una influencia sociocultural transformadora en la historia. Esta es una concepción donde la iglesia es considerada una institución que debe influir cultural y políticamente: para los postmilenaristas pietistas, la Iglesia evangélica es una reserva moral en donde los principios bíblicos no son sólo para los creyentes, sino para toda la sociedad. Por tanto, los líderes evangélicos se autoconciben como "llamados" a una misión especial, a saber: no sólo a pastorear las ovejas de sus iglesias, sino también a pastorear las ovejas desde los espacios políticos. Aquellos que se oponen, deben ser excluidos social y políticamente y se les debe negar sus derechos sociales, políticos y jurídicos, porque son considerados "antibíblicos", es decir, contrarios a los "valores" que dispone este libro sagrado para toda sociedad. Y todas las crisis y manifestaciones de la naturaleza son consideradas como el enojo de Dios por culpa de las decisiones políticas que benefician a "los malos". 
En cambio, desde la visión postmilenarista geonómica, las personas no se enfocan ni en las esperanzas milenarias ni en la visión interventora de la Iglesia. Por una parte, cree que la evolución gradual traerá el milenio; y por la otra, que el ser humano mismo debe introducir la nueva era adoptando una política constructiva de mejoras sociales y políticas que beneficien a todos. Hay una clara diferenciación entre Iglesia y Estado, y la primera está al servicio del segundo en cuanto promueve políticas que beneficien a toda la sociedad, especialmente a los excluidos y marginados de la sociedad. El principal interés es el deseo de un orden social en el que la dignidad y la libertad de cada uno, especialmente de los "más pequeños" de los seres humanos, sea honrada y protegida; en el que la fraternidad del ser humano se exprese en la posesión común de los recursos económicos de la sociedad; y en el que el bien espiritual de la humanidad esté colocado por arriba de todos los intereses privados, ya sean religiosos, económicos y políticos. Por ello, Schäfer señala que "el postmilenarismo tiene dos implicancias significativas: el nacionalismo y la ética social” (Schäfer 1992, 34).

Este análisis puede parecer dicotómico, pero en realidad sólo se trata de una descripción de los grupos evangélicos que participan políticamente y que se pueden ver como "evangélicos de derecha" y "evangélicos de izquierda". El espectro es mucho más complejo y relacional que lo que se avizora. En este sentido, también se trata de la responsabilidad política que tienen los partidos y conglomerados políticos. Por ejemplo, los partidos de la derecha permiten y apoyan, a veces sin concordar, a candidatos evangélicos y buscan el apoyo evangélico, ya que lo consideran un actor relevante en la política nacional. En cambio, los grupos de izquierda, por su fuerte proceso de secularización y laicismo, no permiten o no buscan ni apoyan a candidatos evangélicos por considerarlos fundamentalistas, irrelevantes o políticamente incorrectos. Los sectores de izquierda desconocen la historia desde 1973 hacia atrás cuando los evangélicos, especialmente los pentecostales, eran aliados políticos, social y económicamente de la izquierda.

Por esa razón, los sectores evangélicos serán cada vez más de derecha, más fundamentalistas y apoyarán a candidatos y a líderes políticos dictatoriales que deterioran un sano ambiente democrático. $Y$ lo que es peor de parte de la izquierda no hay autorreflexión al respecto, ya que culpan a los evangélicos de fanáticos e ignorantes fundamentalistas, desprecian y mantienen un sinnúmero de añejos prejuicios y estereotipos. En cambio, los sectores de derecha construyen mejores y más eficaces estrategias de articulación con estos sectores evangélicos, sumando a su perspectiva y agenda ideológicopolítica las concepciones socioteológicas de estos grupos. De aquí, podemos vislumbrar un futuro que intensificará las diferencias sociales y aumentarán las divisiones sociales, políticas, económicas y religiosas, las cuales se manifestarán claramente en el mundo evangélico, y lo peor es que las divisiones políticas separarán a los evangélicos. 


\section{Conclusiones}

Pudimos ver que los líderes evangélicos partieron brindando su apoyo a Ricardo Lagos en el 2000. Obviamente ningún apoyo es gratuito. Pese a manifestar una aparente unidad, pronto se reveló un desacuerdo en el lugar del Te Deum evangélico, instancia que nunca ha generado unidad entre los evangélicos. En segundo lugar, los evangélicos comenzaron a evangelizar los espacios públicos y políticos con el reconocimiento social, político y simbólico de sus líderes. En tercer lugar, los medios derribaron los mitos políticos del apoliticismo o la izquierdización o derechización de la política evangélica. En cuarto lugar, pese a la visibilidad y al reconocimiento que los evangélicos comienzan a tener, siguen siendo discriminados e invisibilizados, por ejemplo, con la ausencia de capellanes en las Fuerzas Armadas, de orden y en los servicios de salud. Por último, pese a que los líderes respaldan a candidatos presidenciables y del Congreso, los evangélicos, al no tener experiencia política, siguen siendo excluidos de los ministerios, secretarías y subsecretarías de gobiernos. Por un lado, los candidatos alcaldicios, concejales o al congreso no son apoyados por los mismos evangélicos, pues la población evangélica sigue considerando que su rol político llega sólo hasta el voto y no en la participación. Por otro lado, el mito de la libertad de conciencia política en Chile se hizo de manifiesto en el año 2009, no tanto porque un determinado obispo evangélico hiciera un llamado a los evangélicos a votar por cierto candidato, porque esto ya se había realizado hace 10 años, sino porque otros líderes evangélicos salen a criticarlo abiertamente por su declaración pública, lo cual ellos hicieron de manera solapada.

No es la libertad de conciencia lo que les preocupa, sino manifestar un aparente y homogéneo apoyo del mundo evangélico a los sectores de derecha. Así, en la última campaña, se avizoraron los primeros conflictos entre evangélicos, sectores sociales y políticos liberales. Es la lucha entre la "ayuda pluralista" y la ideología del ombliguismo que defiende un importante número de líderes evangélicos conservadores. Por tanto, no es la libertad de conciencia la que se defiende, sino más bien, una domesticación y una derechización de la conciencia política evangélica, por ende, no interesan las mejoras salariales, las regulaciones bancarias, los cambios en el sistema previsional, etc. Por ese motivo, los evangélicos son apoyados por los sectores y los partidos de derechas, no porque la derecha defienda sólo la ideología del ombliguismo, sino también porque los evangélicos políticos no atacan lo intereses el conglomerado político-empresarial de la derecha. De este modo, la derecha política tiene un aliado en los sectores populares de Chile: los evangélicos.

En efecto, el mito del Chile para Cristo produjo un nuevo enfoque a las políticas evangélicas y a los evangélicos políticos. Una especie de refundacionalismo a la política chilena pervertida por el liberalismo político, social y simbólico. Por lo tanto, los evangélicos han fundado distintas estrategias: a) En primer lugar, tiendas políticas con el fin de crear una agrupación de partidos evangélicos; b) En segundo lugar, una plataforma para candidato a alcaldes y 
al congreso para su formación con talleres y coaching, de este modo, adoctrinan políticamente a los candidatos para ser electos y reelegidos. Un elemento importante ha sido la formación de nuevos líderes religiosos partiendo desde la enseñanza de educación media hasta las universidades para aprender a hacer política y a conocer las estrategias políticas; por lo tanto, hoy los evangélicos chilenos comienzan a formar un proyecto político. Por ahora, se trata de grupos interesados en los gobiernos comunales (alcaldes y concejales) y en el parlamento (diputados y senadores). Es un incipiente grupo de políticos evangélicos de derecha proideología del ombliguismo, pero, posiblemente en el futuro, incorporen temas sociales, económicos, culturales de la sociedad o materias relacionadas con los pueblos originarios, migrantes, pobreza, salud, vivienda y previsión social.

En consecuencia, ya no se busca un político evangélico, sino un evangélico político; ya no se busca resaltar la identidad política-partidista, sino la política religiosa denominacional; ya no se intenta luchar por los beneficios sociales, la anticorrupción, la violencia, la tolerancia a los migrantes, la salud, la educación laica, gratuita y pública, sino que más bien se busca evangelizar los espacios públicos, políticos y estatales. Son un sector importante de los evangélicos en Chile que irrumpen en el ámbito público e inician una nueva experiencia: salir de la invisibilización.

\section{Bibliografía}

Berkhof, Louis. 1976. Teología sistemática. Grand Rapids MI USA: Eerdmans Publishing Co. 1976

Barrios, Catalina. 2017. «Los evangélicos de Parisi». El Mostrador, Acceso el 12 de julio de 2018. http://www.elmostrador.cl/noticias/pais/2017/02/21/los-evangelicos-deparisi/

Canales, Hermes. 2000. Firmes y adelante. El largo proceso legislativo hasta obtener la ley de promulgación de igualdad jurídica de las iglesias. Breve síntesis histórica de algunos hechos relevantes de la iglesia Evangelina chilena. Santiago: Barlovento impresores, 2000.

Couch, Mal (ed).1999. Diccionario de Teología Premileniarista. Grand Rapids MI USA: Portavoz. 1999.

Cid, Ignacio. 2015. «Javier Soto es el problema». El Mostrador. Acceso el 12 de julio de 2018. http://www.elmostrador.cl/noticias/opinion/2015/01/08/javier-soto-es-elproblema/?v=desktop 
D'Epinay, Christian Lalive. 1968. El Refugio de las Masas. Santiago: Editorial del Pacífico. 1968

D'Epinay, Christian Lalive. 1972. «Sociedad dependiente, clases populares y milenarismo. Las posibilidades de mutación de una formación religiosa en el seno de una sociedad en transición. El pentecostalismo chileno», Cuaderno de la Realidad Nacional 14: 96-112.

Emol. 2000, septiembre 17 «Diversas reacciones por ausencia de Lagos en $\mathrm{Te}$ Deum». http://www.emol.com/noticias/nacional/2000/09/17/32796/diversasreacciones-por-ausencia-de-lagos-en-te-deum.html (Consultado el 12 de julio de 2018)

Emol. 2013, marzo 16. «Diputado Ojeda (DC) acusa discriminación en el Ejército contra capellanes evangélicos». http://www.emol.com/noticias/nacional/2013/03/16/588727/diputadoojeda-dc-acusa-discriminacion-en-el-ejercito-contra-capellanesevangelicos.html (Consultado el 12 de julio de 2018)

El Mercurio 2001, agosto, 12 «Evangélicos piden a Lagos instaurar el día de la Biblia». El Mercurio, C2.

El Mercurio. 1999, septiembre 29. «Candidatos a la conquista del voto evangélico». El Mercurio, C2.

El Mercurio. 2004, noviembre 28. «La revolución evangélica». El Mercurio, http://diario.elmercurio.com/detalle/index.asp?id=\%7B17ad3937-857a494a-adff-0555a2086768\%7D

Emol. 2015, septiembre 13. «Te Deum evangélico: Obispos ven crisis de confianza en el país y piden "erradicar" corrupción». Emol, http://www.emol.com/noticias/Nacional/2015/09/13/749692/Te-Deumevangelico-Obispos-reconocen-crisis-de-confianza-en-el-pais-y-hacenllamado-a-la-esperanza.html

Emol. 2000, septiembre 17. «Diversas reacciones por ausencia de Lagos en Te Deum». Emol, https://www.emol.com/noticias/nacional/2000/09/17/32796/diversasreacciones-por-ausencia-de-lagos-en-te-deum.html (consultado el 12 de octubre de 2018)

El Libero. 2017, septiembre 12. El Libero http://ellibero.cl/actualidad/el-otroimpasse-de-un-presidente-en-un-te-deum-evangelico-el-protagonistafue-ricardo-lagos/

Fediakova, Evguenia. 2013. Evangélicos y sociedad en Chile: dejando "el refugio de las masas", 1990-2010. Concepción: CEEP-IDEA, 2013.

Fonseca, Josué. 2013. «Cómo votan los Evangélicos». El Mostrador. Acceso el 30 de mayo de 2018. http://www.elmostrador.cl/noticias/opinion/2013/12/17/como-votan-losevangelicos/ 
Fontaine, Arturo y Beyer, Harald. 1991. «Retrato del movimiento evangélico a la luz de las encuestas de opinión pública». Estudios Públicos 44: 152.

Guerra, Mónica. 2005, agosto 23. «Lavín se comprometió con los evangélicos». El Mercurio, C6.

La Tercera. 2000, enero 7. «Evangélicos por Lagos». La Tercera, 20

Herrera, Mariela. 1999, agosto 15. «¡A ponerle Pino! La carrera presidencial del pastor evangélico». El Mercurio, D6-D7. http://diario.elmercurio.com/detalle/index.asp?id=\{6b61a694-3187-4fe29a47-387d5e8f7db6\}

Hormachea, David. 2017. «Revuelo ¿Debió David Hormachea llamar a votar en las primarias de Chile Vamos por Ossandón?»Cosmovisión. Acceso el 12 de julio de 2018. http://cosmovision.cl/revuelo-debio-davidhormachea-llamar-votar-las-primarias-chile-ossandon/

Hormachea, David. 2010. «Declaración Política del doctor David Hormaechea». Prensa Evangélica: 6

Isaac Daniel. 2013. «Obispo Hédito Espinoza. Tedeum Evangélico 2013». Video rodado en 2013. Video en YouTube, 21:01, publicado. Acceso el... de... https://www.youtube.com/watch?v=Qcoamln0DPU

Jarpa, Josaphat. 2017. «Evangélicos y Política en Chile en búsqueda de la gloria y el poder», Le Monde Diplomatique. Acceso el 12 de octubre de 2018. https://www.lemondediplomatique.cl/Evangelicos-y-Politica-enChile-en.html

Lagos, Humberto. 1988. Crisis de la esperanza. Religión y autoritarismo en Chile. Santiago: Presor y Lar. 1988.

Loewe, Daniel. 2013. «iAleluya! La teología política de Matthei». El Mostrador: 1. Acceso el 12 de octubre de 2018 http://www.elmostrador.cl/noticias/opinion/2013/11/27/aleluya-lateologia-politica-de-matthei/

Ortiz, Juan. 2009. Historia de los evangélicos en Chile 1810-1891: de disidentes a canutos liberales, radicales, masones $y$ artesanos. Concepción: CEEP EDICIONES, 2009

Ossa, Manuel. 1991. Lo Ajeno y lo propio. Santiago: Rehue, 1991

Ossa, Manuel. 1990. Espiritualidad popular y acción política. Santiago: Rehue, 1990

Radio Sago. 2017. «El otro impasse de un presidente en un tedeum evangélico: el protagonista fue Ricardo Lagos». https://www.radiosago.cl/resumen-noticias-martes-12-septiembre-2017sagoregion/

Mansilla, Miguel. 2016. La buena muerte. La cultura del morir en el Pentecostalismo. Santiago: UNAP-RIL 
Mansilla, Miguel. 2017a. «El Tedeum Evangélico: de la falacia del apoliticismo al realismo partidista». El Desconcierto. Acceso el 12 de julio de 2018. http://www.eldesconcierto.cl/2017/09/18/el-tedeum-evangelico-de-lafalacia-del-apoliticismo-al-realismo-partidistal

Mansilla, Miguel. 2017b. «La influencia evangélica en las elecciones presidenciales». El Desconcierto: 16-12. Acceso el 12 de julio de 2018. http://www.eldesconcierto.cl/2017/12/16/la-influencia-evangelica-en-laselecciones-presidenciales/

Mansilla, Miguel y Luis Orellana. 2018. Evangélicos y política en chile 19601990. Política, apoliticismo y antipolítica. Santiago: Ril-UNAP, 2018

Rivière, Gilles. 2004. «Bolivia: el pentecostalismo en la sociedad aimara del Altiplano». En Gracias a Dios y a los Achachilas. Ensayos la sociología de la religión en los Andes, compilado por Alison Spedding, 259-294. La Paz: ISEAT-PLURAL

Ramírez, Pedro y Gabriela Pizarro. 2017. «Las pugnas y negociaciones para instalar en Chile el poder político evangélico». CIPER. Acceso el 12 julio de 2018. http://ciperchile.cl/2017/10/26/las-pugnas-ynegociaciones-para-instalar-en-chile-el-poder-politico-evangelico/

Rivas, Claudia. 2013. "Matthei da manotazos de ahogado y apela al voto evangélico». El Mostrador. Acceso el 12 de julio de 2018. http://www.elmostrador.cl/noticias/pais/2013/11/04/matthei-damanotazos-de-ahogado-y-apela-al-voto-evangelico/

Salinas, Claudio. 2005, diciembre 24. «Evangélicos evalúan apoyos políticos para la segunda vuelta». El Mercurio, C4.

Schäfer, Henrich. 1992. Protestantismo y crisis social en América Central. Costa Rica. Editorial DEI.

Sierra, A. 2009. «Siguen los coletazos por inclusión de gays en franja de piñeras».El Mostrador. En Archivo Chile, Centro de Estudios Miguel Enrique (CEME). Acceso el 12 de octubre de 2018. http://www.archivochile.com/Chile_actual/elecciones_2009/doc_gen/ele cc2009_docgen0001.pdf

Teave, Teamai. 2010, enero 5. «Líderes evangélicos dan giro y llaman a votar por Frei». El Mercurio, http://www.emol.com/noticias/nacional/2010/01/05/392377/lideresevangelicos-dan-giro-y-llaman-a-votar-por-frei.html (Consultado el 10 de mayo de 2018)

Turpo, Osvaldo. 2008. «La netnografía: un método de investigación en Internet». EDUCAR, 42: 81-93.

Usach. 2017, marzo 16. «Nuevo presidente de la Feusach, Patricio Medina: Me preocupa que peligre el apoyo a las instituciones estatales»". Universidad de Santiago de Chile. http://www.usach.cl/news/nuevo- 
presidente-la-feusach-patricio-medina-me-preocupa-peligre-apoyo-lasinstituciones-0

Vilches, Israel. 2017. «[Candidatos] ¿Quiénes fueron los primeros evangélicos en el Congreso nacional chileno? Revista Cosmovisión: 1. Acceso el 30 de mayo de 2018. http://cosmovision.cl/candidatosquienes-fueron-los-primeros-evangelicos-congreso-nacional-chileno/

Villavicencio, Gustavo. 2008, octubre 12. «Ahora a los niños les tendrán que enseñar en los colegios que significa el 31 de octubre». El Mercurio, D23. 